\title{
Discurso acadêmico: a regulação do poder disciplinar e do panóptico
}

\author{
Beatriz Gil ${ }^{1}$ \\ Universidade Estadual Paulista - IBILCE/UNESP, São José do Rio Preto, SP, Brasil
}

Fernanda Correa Silveira Galli²

Universidade Federal de Pernambuco - UFPE, Recife, PE, Brasil

Resumo: O objetivo deste trabalho é observar a operacionalização do poder disciplinar e do panóptico nas práticas que perfazem o discurso acadêmico atual. Para tal, emprega-se uma metodologia genealógica, conforme direção proposta por Foucault (1979), por meio da análise dos sistemas de métricas acadêmico e científicas do banco de dados Google Acadêmico e do índice $\mathrm{H}$, ambos marcadores acadêmicos de produtividade. Os resultados apontam que os princípios da visibilidade e da inverificabilidade do panóptico são usados como ferramentas disciplinares do pesquisador, colocando-o como uma peça, um corpo dócil na maquinaria de produção da academia, cuja função produtiva é a publicação de textos científicos.

Palavras-chave: Poder disciplinar; Panoptismo; Discurso acadêmico; Sistema de métricas.

Title: Academic discourse: the regulation of disciplinary power and of the panoptic

Abstract: The purpose of this article is to analyze how the disciplinary power and the panopticon work within the practices that are part of the academic discourse nowadays. To fulfill this purpose, it was used a genealogical method, according to Foucault (1979), through the analysis of the Google Academic database and the H-index, both academic markers of productivity. The results point out that the principles of visibility and unverifiability of the panopticon are used as the researcher disciplinary tools, placing him/her as a piece, a docile body in the production machinery of the academy whose productive funtion is the publication of scientific texts.

Keywords: Disciplinary power; Panopticism; Academic discourse; Metric system.

\footnotetext{
${ }^{1}$ Doutoranda em Estudos Linguísticos (Universidade Estadual Paulista - IBILCE/UNESP). Orcid: https://orcid.org/0000-0002-4534-5366

E-mail: beatriz gil24@hotmail.com

${ }^{2}$ Doutora em Linguística Aplicada (Universidade Estadual de Campinas - UNICAMP), Docente do Departamento de Letras, do Centro de Comunicação e Artes (CAC), na Universidade Federal de Pernambuco (UFPE). Orcid: https://orcid.org/0000-0002-4499-2908

E-mail: fcsgalli@hotmail.com
} 


\section{Introdução}

Não há fatos eternos, como não há verdades absolutas.

(Nietzsche)

Mudanças nos paradigmas de pensamento provocam impactos imensuráveis na(s) forma(s) de vida(s). No século XX, é possível observar grandes mudanças na forma de se conceber as Ciências Humanas e Sociais a partir da virada linguística do Estruturalismo e, tempos depois, do chamado Pós-Estruturalismo, confirmando a tese nietzschiana de que a verdade é mais um construto social do que algo imutável, não-humano e não-histórico.

O Estruturalismo, cujos pressupostos enraízam-se em Saussure e em suas considerações sobre linguagem é, como seu próprio nome evoca, organizado em torno da noção de estrutura. Em linhas gerais, Saussure (1916) concebe a linguagem como um sistema de significação e seus elementos são colocados em relação, ou seja, um depende do outro. A base da linguagem é o signo, dicotomizado em significado vs. significante. Além dessa dicotomia, ele postula outras, tais como: língua vs. fala, sincronia vs. diacronia, sintagma vs. paradigma. Dentro desses pares, Saussure seleciona quais são seus objetos de pesquisa (língua, sincronia, sintagma), descartando os outros de acordo seu interesse. Esses binarismos inserem a noção de diferença, fundamental nos estudos saussurianos - uma coisa é aquilo que a outra não é.

Essa episteme torna-se, na visão de Peters (2000), um megaparadigma transdisciplinar, contribuindo para integrar as Humanidades e as Ciências Sociais, uma vez que extrapola os domínios linguísticos e passa a inspirar pesquisadores das mais diversas áreas, tais como: LeviStrauss, na Antropologia; Lacan, na Psicanálise; Barthes, na Literatura; Althusser, na Filosofia e no Marxismo; dentre outros. Não há como se falar em Ciências Humanas no século XX sem pensar na questão das estruturas - seja para corroborá-las ou refutá-las. A expansão das ideias desenvolvidas dentro da Linguística para outros campos é denominada, por Gregolin (2004, p.21), como "a virada linguística".

Entretanto, seu caráter cientificista - cujo interesse são as estruturas e a sistematização, além dos binarismos, se pensarmos nas dicotomias de Saussure - gera críticas e alimenta novas considerações sobre o mundo. Mesmo que problematizados inúmeras vezes, é somente a partir das condições de produção sócio-históricas permitidas por Saussure, aliado aos pensamentos de Marx sobre a sociedade-história e Lacan sobre o inconsciente, que são possíveis as releituras e os deslocamentos originários do pós-estruturalismo.

Para Peters (2000, p. 28), o pós-estruturalismo pode ser caracterizado "como uma forma de pensamento, um estilo de pensar, uma forma de escrita". Ele ainda chama a atenção 
para o enquadramento de vários pesquisadores e filósofos diferentes dentro desse termo, assim não deve ser entendido como uma unidade homogênea. Pelo contrário, a desconstrução e a emersão da heterogeneidade são algumas de suas características. 0 pesquisador defende que, além de não ser possível separar o pós-estruturalismo da tradição estruturalista em suas várias áreas, outra característica do seu desenvolvimento, na França, foi a filiação de seus pensamentos aos de Nietzsche, em especial à sua crítica da noção corrente de verdade como algo absoluto e incontestável.

Assim como o estruturalismo ultrapassa as fronteiras geográficas da Europa espalhando-se pelo mundo, o pós-estruturalismo também se difunde. Nos Estados Unidos, por exemplo, é notória a figura de Derrida, reconhecido filósofo da desconstrução, uma vez que questiona a estrutura e sua centralidade. Uma de suas críticas mais difundidas é em relação às dicotomias do estruturalismo, as quais defendem que toda polarização acarreta uma hierarquização na qual um dos polos se coloca em privilégio ao outro, o que causa disparidades. Essa reflexão torna-se central.

Nesse sentido, julga-se importante discutir o senso comum de que os paradigmas da ciência e do pensamento se excluem e se substituem, colocando-se em forma dicotômica de oposição - estruturalismo vs. pós-estruturalismo. Esse senso comum leva ao equívoco de que "um é tudo aquilo que o outro não é", se acatarmos a ideia de valor de Saussure, e, talvez mais complexo que isso, a questão de que um dos polos se coloca em posição de valorização e superioridade ao outro, se aplicarmos a ótica de Derrida.

O que ocorre, muitas vezes, além da refutação de algumas ideias vigentes, é o englobamento de um paradigma no outro, em um movimento no qual se absorvem algumas reflexões pertinentes, expandem-se ideias embrionárias, acrescentam-se aspectos não considerados e dá-se luz a outros não desenvolvidos. Até a própria materialização linguística da terminologia "pós-estruturalismo" nos leva a isso: ela se constitui pela presença e visibilidade do estruturalismo.

Peters (2000, p.35-38) discute afinidades passíveis de serem observadas entre os dois movimentos. A primeira delas é que ambas partem de uma crítica à filosofia humanista do Renascimento e ao seu sujeito iluminista - o homem é consciente, racional e centro de interesse. A consideração foucaultiana de o homem ser uma invenção recente trata dessa questão. Gicoia Jr. (2016) explica que antes do século XVIII o homem não existia enquanto sujeito e objeto de interesse, ele só é considerado após a passagem, permitida pelas reflexões do Renascimento e do lluminismo, do mundo teocêntrico - Deus ao centro - ao mundo antropocêntrico - Homem ao centro. ${ }^{3}$

Esse sujeito racional e absoluto, então, passa a vigorar como o centro da ciência, movimento esse refutado posteriormente por ambas correntes - estruturalismo e pósestruturalismo. Outro ponto de intersecção é a preocupação com a linguagem. Ambos os

\footnotetext{
${ }^{3}$ Disponível em: https://www.youtube.com/watch?v=5XcxVHo4ozc. Acesso em: 23 jul. 2019.
} 
movimentos entendem a língua e os signos linguísticos com função reflexiva, dependentes de outros pontos de vista, e não referenciais e absolutos, por exemplo.

O pós-estruturalismo, entretanto, distancia-se do estruturalismo ao colocar holofote em elementos não priorizados por este: a História, relegada a segundo plano nos recortes saussurianos; o questionamento das dicotomias fundadoras a partir do princípio de que elas não são fundacionais ou exclusivas, como se pressupunha; a preocupação com a diferença, identidade e poder como construção social, e não como metanarrativas, são alguns pontos de distanciamento. Desses embates, dentro do contexto favorável permitido pelo pósestruturalismo, surge a análise do discurso de linha francesa, cujo interesse é, em diferentes perspectivas, compreender os sentidos a partir da materialidade linguística.

Os motivos descritos explicam por que, apesar de não se intitular como pósestruturalista, é possível enquadrar Michel Foucault, cerne teórico deste trabalho, nesse movimento. A História está no centro de toda sua obra, como, por exemplo, quando traça uma relação indissociável entre sujeito e contexto sócio-histórico/de produção no qual está inserido. Ao aplicar esse raciocínio do historiador em sua própria condição de produção, é possível entender melhor os atravessamentos que sofre e são refletidos em sua obra, uma vez que se insere neste momento histórico da desconstrução de pensamentos tomados como absolutos, conforme explicado nos parágrafos anteriores.

Devido à extensão e à variedade no escopo de sua obra - sanidade, sexualidade, vigilância, entre outros - há inúmeras tentativas de classificação de sua obra. De acordo com Veiga-Neto (2007, p. 35), talvez a mais difundida delas seja a tripartição do pensamento, com critério metodológico-cronológico, ao propor um agrupamento pautado pelo momento da publicação de suas obras, a saber: (i) Arqueologia: História da loucura (1961) até A arqueologia do saber (1969); (ii) Genealogia: A ordem do discurso (1971) a História da sexualidade - a vontade de saber (1976); (iii) Ética: História da sexualidade - o uso dos prazeres (1984) e O cuidado de si (1984).

Outra consideração relevante a respeito dos "três Foucaults" são as perguntas norteadoras de cada uma de suas fases: (i) que posso saber?, (ii) que posso fazer?, e (iii) quem sou eu? (DELEUZE, 1991 apud VEIGA-NETO, 2007, p. 37). Propor uma classificação estanque e cronológica dos pensamentos de Foucault, filósofo da pós-estrutura, parece um tanto paradoxal. Veiga-Neto (2007, p. 38) destaca ser polêmica essa periodização, não em relação às suas metodologias arqueológicas, genealógicas ou éticas de análise, mas ao levar a uma pressuposição de que cada fase é independente e diferenciada da outra. Na realidade, as obras e as fases não são uma ruptura de uma com a outra, e sim uma "incorporação de uma pela outra".

Na tentativa de evitar a armadilha da simplificação, Veiga-Neto (2007, p. 40), com base em Morey (1991), propõe a classificação em três domínios, com base na nossa ontologia histórica. Assim, tem-se a seguinte constituição:

(i) Ser-saber: o saber rege, somos sujeitos de conhecimento; 
(ii) Ser-poder: ação de uns sobre os outros, somos sujeitos de ação sobre os outros;

(iii) Ser-consigo: a ação de cada um consigo mesmo, somos sujeitos de ação moral sobre nós mesmos.

A presente abordagem insere-se no domínio do ser-poder, já que se interessa por traçar reflexões sobre o discurso acadêmico e suas relações de poder. Objetivamos, então, a partir da metodologia genealógica de Foucault $(1979,1999)$, observar a operacionalização do poder disciplinar e do panoptismo nas práticas do discurso acadêmico. Para tanto, buscamos analisar dois dispositivos que funcionam nesse discurso: (i) o banco de dados Google Acadêmico e (ii) o Índice-H, um dos indicadores de produtividade mais significativos dentro da academia. ${ }^{4}$

\section{O domínio do ser-poder: o discurso, as relações de poder e o panóptico}

Ninguém pode entrar duas vezes no mesmo rio. [...] O real é sempre fruto da mudança, ou seja, o combate entre os contrários.

(Heráclito)

Ainda que os contextos de produção sócio-históricos de Foucault e Heráclito, filósofo grego, sejam completamente distintos - meados do século XX, no primeiro, e 500 a.C., no segundo - é possível extrair da epígrafe desta seção algumas noções fundamentais que perpassam os pensamentos foucaultianos.

A primeira delas é a ideia de que o contexto de produção nunca será o mesmo. Da mesma forma que não é possível se banhar na mesma água de um rio duas vezes - já que na segunda vez será em outro momento e a água anterior já terá corrido-, não se pode enunciar no mesmo contexto, uma vez que a história e os sujeitos mudam, ainda que seja de um minuto para outro. Essa questão é fundamental devido ao fato de que, por meio dela, chega-se ao ponto no qual um sujeito só pode enunciar aquilo que é permitido em determinado momento pelas suas condições históricas.

A segunda noção possível de extrair de Heráclito é a ideia do "combate entre contrários". Para Foucault, a base de toda a relação humana são as relações de poder, compostas sempre por dois polos - dominado vs. dominante, e nas quais fica implícita a questão do combate e da resistência, conforme desenvolveremos a seguir.

Já que, nesta abordagem, o foco é a análise do discurso de perspectiva foucaultiana, a definição do termo discurso é nosso ponto de partida. Para Foucault (2008, p. 132), discurso é "um conjunto de enunciados, na medida em que se apoiem na mesma formação discursiva".

\footnotetext{
${ }^{4}$ Nas seções subsequentes, explicamos os conceitos citados.
} 
Nessa definição, destacam-se, então, dois outros conceitos: o de enunciado e o de formação discursiva (FD).

Gregolin (2004, p. 24) pontua que o enunciado é a "unidade elementar do discurso", e se caracteriza por ser "um conjunto de signos em função enunciativa". Em relação à formação discursiva, Foucault a conceitua como:

No caso em que se puder descrever, entre um certo número de enunciados, semelhante sistema de dispersão, e no caso em que entre os objetos, os tipos de enunciação, os conceitos, as escolhas temáticas, se puder definir uma regularidade (uma ordem, correlações, posições e funcionamentos, transformações) diremos, por convenção, que se trata de uma formação discursiva (FOUCAULT, 2008, p. 43).

A partir da FD, é possível atribuir sentidos aos discursos por meio da regularidade e da dispersão, de modo a determinar interpretações possiveis aos enunciados e excluir outras. Díaz (2012, p. 86) trata a FD como um “jogo contratante de permissões e restrições". Essas permissões e restrições podem ser entendidas como as relações de poder que permeiam todo e qualquer discurso, toda e qualquer interação humana, uma vez que, para Silva (2004), é por meio do poder que se determina o que é verdadeiro ou falso em uma época.

Pensar no poder, na perspectiva de Foucault, entretanto, é abandonar alguns préconceitos. Comumente, atribui-se o poder a pessoas específicas que ocupam determinadas posições sociais, e assim o poder estaria nas mãos de políticos, por exemplo. Outro equívoco é o poder relacionar-se com quem tem dinheiro ou quem tem conhecimento.

Ao contrário disso, o poder não é algo fixo em posições sociais, em sujeitos específicos, ele não é algo que alguém tem ou não, ele "não se dá, não se troca nem se retoma, mas se exerce, só existe em ação" (FOUCAULT, 1979, p. 175). Trata-se de uma maquinaria na qual "ninguém é titular", destaca Foucault (1979, p. 219). Díaz (2012, p. 121) argumenta que o poder é a relação de "quem incita - quem é incitado", ou seja, de um que conduz a ação de outro(s). O poder, nessas bases, opera por meio de relações de forças.

Ele funciona em rede e um mesmo sujeito posiciona-se nessa rede de forma a exercer o poder e a sofrer sua ação. Então, não é algo que vem de cima para baixo. Na verdade, Foucault (1979) afirma que o seu funcionamento nos níveis mais baixos, nos agentes reais, é o que o desloca, o expande e o modifica, permitindo a estrutura de dominação. O poder, logo, está nas microrrelações do dia a dia, na microfísica, não nas macroestruturas.

Seguindo os raciocínios de Díaz (2012), o foco de interesse não é descobrir "o que é o poder", e sim, "como se exerce o poder". Foucault (1979) considera em sua genealogia que o surgimento de uma burguesia, fruto de um capitalismo exacerbado, cujas necessidades provocam a Revolução Liberal dos séculos XVIII e XIX, gera um deslocamento de uma sociedade centrada na lei, cujas penalidades calcavam-se na vingança, para uma sociedade 
centrada no padrão, cujo mecanismo de repreensão é o parâmetro de normalidade. Assim, o poder não é mais visto como punitivo; ele é disciplinar, e seu intuito é garantir que todos ajam conforme a norma.

Essa "norma" é particularizada dentro de cada instituição, cuja responsabilidade é domesticar, disciplinar o indivíduo para que se enquadre nela. A partir dessa "normalidade", passa-se a operacionalização de binarismos - "o louco" vs. "o são", por exemplo -, nos quais um lado produz, alimentando a maquinaria capitalista da sociedade, e o outro foge à produção, devendo ser, portanto, disciplinado. Foucault (1979) afirma que as técnicas de poder foram inventadas com a finalidade de responder às exigências da produção dessa burguesia.

Destarte, a criação burguesa de um poder disciplinar fabrica o que o historiador (1979) denomina de "corpos dóceis", ou seja, o "indivíduo domesticado". A disciplina passa a ser um mecanismo mais benéfico de controle do que a punição, uma vez que a consequência dessa disciplina não é o medo ou a revolta, e sim a produção, isto é, o indivíduo disciplinado produz o que quer que seja que a sociedade precisa que ele faça. Além disso, a possível resistência e o possível combate provenientes do atrito entre dominado vs. dominante diminuem, e não só o dominante, mas também o dominado passa a validar a relação e o sistema.

Díaz (2012, p. 133) exemplifica o funcionamento desse poder em dispositivos concretos (cárcere, escola) integrados a partir de substâncias qualificadas (prisioneiro, aluno) e de funções (controle, educação). Essas instituições produtoras de disciplina operam, ainda que com estratégias diferentes, segundo o modelo do cárcere panóptico. É o panoptismo que permite o poder continuar operando em sua forma disciplinar e ao indivíduo permanecer no local correto em que deve estar para que possa produzir verdades e saberes.

Termo cunhado por Bentham, em 1785, o panóptico (pan: tudo, toda; óptico: visão), conforme descrito por Foucault (1979, p. 210), é uma estrutura carcerária onde há uma torre central, a qual permite visibilidade para o seu exterior e não para seu interior, e uma construção periférica dividida em celas que possuem duas janelas - uma que se abre para seu interior e outra para o seu exterior, permitindo que a luz ilumine a cela por completo. Colocase, então, um vigia na torre e "um louco, um doente, um condenado, um operário ou um estudante" na cela. Há uma dissimetria clara na construção, o que Foucault (1999, p. 225) chama de uma dissociação do par "ver-ser visto": "no anel periférico, se é totalmente visto, sem nunca ver; na torre central, vê-se tudo, sem nunca ser visto".

O poder é operado "por iluminação, transparência" já que é a visibilidade do trancafiado observado, a todo momento, por um vigia, que faz com que esse não se rebele. Essa vigilância constante faz com que cada indivíduo passe a observar a si mesmo - a vigilância agora não é só do guarda localizado na torre central, mas também dos outros encarcerados à sua volta e, mais forte que isso, a "vigilância sobre e contra si mesmo" (FOUCAULT, 1979, p. 218). 
Foucault (1999) explica que o principal efeito do panóptico é criar no encarcerado um estado de consciência permanente sobre sua visibilidade, assegurando o funcionamento automático do poder. O poder, portanto, funciona por dois mecanismos: de ser visível, como já foi relatado, e de ser inverificável, isto é, nunca se sabe se está sendo observado de fato, mas é preciso saber que a vigilância pode acontecer a qualquer momento.

A inverificabilidade da vigilância faz com que o vigiado volte, espontaneamente, o olhar a si mesmo, tornando-se seu próprio vigia. Logo, há a internacionalização da norma e a modificação dos comportamentos na tentativa de aproximação do normal e o enquadramento em "certos tipos de sujeito". O poder vigilante, como consequência, beira ao incorpóreo, não tem um corpo físico. Como Oksaka (2011, p. 73) afirma: "trata-se de uma vigilância difusa, mas anônima".

As noções de poder disciplinar e de panóptico são, portanto, essenciais para o desenvolvimento deste trabalho. A seção subsequente apresenta os elementos que serão analisados à luz da proposta sobre poder disciplinar e panoptismo.

\section{A pesquisa genealógica}

A vida só pode ser compreendida, olhando-se para trás; mas só pode ser vivida, olhando-se para frente.

(Kierkegaard)

Gregolin (2004, p. 55) aponta que Foucault defende "três modos de produção histórica da subjetividade": (i) o método arqueológico, na direção passado-presente; (ii) o método genealógico, na direção presente-passado; e (iii) a técnica de si. Independente da técnica escolhida, vê-se a centralidade da história no método. Esta pesquisa preocupa-se com o segundo modo de produção, ou seja, a pesquisa genealógica.

Díaz (2012) postula a genealogia como uma análise cujo ponto de partida é o presente, recuando-se na história. Ressalta-se que esse momento presente, "começo", ponto de partida da genealogia, é uma construção histórica, uma produção humana no tempo. Não uma essência, algo que apenas se extrai do mundo. Nesse sentido, uma pesquisa genealógica busca observar os diversos sistemas de submissão em um discurso, mas não em seu centro, conforme explica Foucault (1979), e sim em suas extremidades, nas instituições mais regionais e locais, onde se torna capilar.

Nela, investiga-se como os mecanismos de controle operam "sem procurá-los na burguesia e sim nos agentes reais (que podem ser a família, a vizinhança, os pais, os médicos etc.)" (FOUCAULT, 1989, p. 185). Para construir nossas considerações sobre a operacionalização do poder disciplinar no discurso acadêmico, via panoptismo, procuramos selecionar dispositivos que se configurariam dentro dessa extremidade do discurso, e não no 
seu centro de funcionamento. Foram selecionados, devido à sua relevância para o discurso acadêmico, dois dispositivos:

(i) O Banco de Dados Google Acadêmico: o Google Acadêmico ou Google Scholar, de acordo com o texto fornecido pela própria plataforma, é uma ferramenta de busca que permite, de maneira simples e rápida, a procura tanto de textos acadêmicos (artigos, teses, livros etc.) relacionados a um tema, quanto a busca por pesquisadores específicos, como na interface da figura abaixo:

Figura 1: Interface da plataforma Google Acadêmico

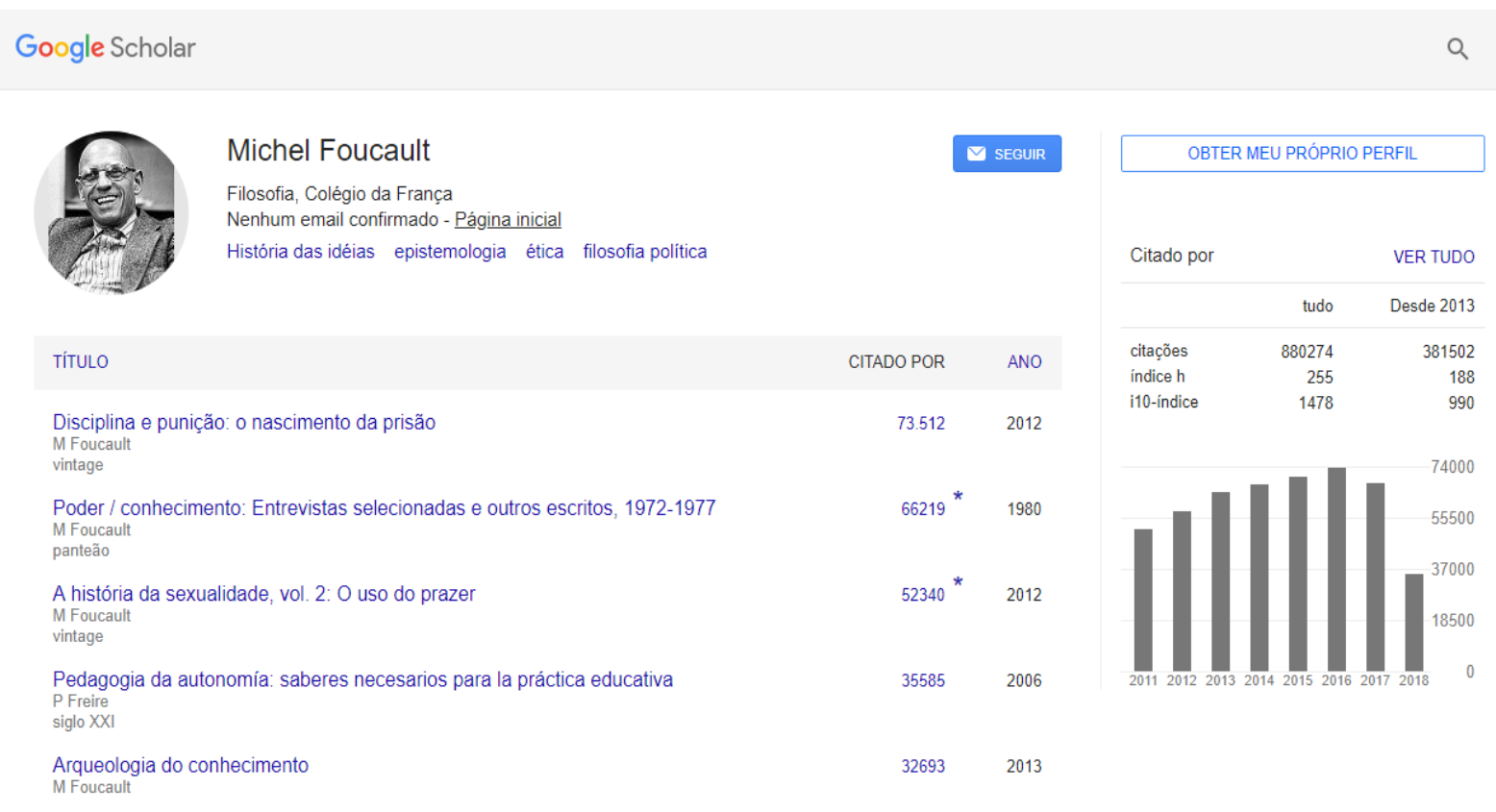

Fonte: Google Acadêmico

O Google Acadêmico é uma ferramenta gratuita e disponibilizada em meio online sem restrições de acesso, motivo pelo qual foi o banco de dados escolhido para esta pesquisa em detrimento de outros. O apelo para uso de tal ferramenta é a de que "o Google Acadêmico ajuda você a encontrar um trabalho relevante em todo o mundo de pesquisa acadêmica." 5 Assim que o usuário cria um perfil - ou um perfil é criado para o usuário pela própria plataforma - é possível organizar toda a produção do pesquisador nesse banco de dados. Ele também passa a ter acesso à quantidade de citações feitas sobre seus trabalhos, suas métricas qualitativas e quantitativas e, dependendo do tipo de perfil criado, quais outros usuários o seguem e o acompanham. Outra possibilidade é criar alarmes para pesquisadores específicos; dessa forma, toda vez que ele publicar algo, recebe-se um alerta.

Além de facilitar a busca por conteúdo acadêmico-científico, a plataforma também

\footnotetext{
${ }^{5}$ Disponível em: https://scholar.google.com/intl/en/scholar/about.html. Acesso em: 23 jul. 2019.
} 
classifica o impacto dos documentos e dos pesquisadores por meio de métricas, organizando as buscas em ordem decrescente de importância: do artigo mais citado para o menos, do pesquisador mais produtivo para o menos. Uma das métricas usadas é o índice- $\mathrm{H}$, tratado a seguir.

(ii) O índice-H de produtividade acadêmica: também conhecido pela sua forma inglesa h-index, foi criado em 2005 pelo físico Jorge Hirsch, da Universidade da Califórnia, e combina em seu cálculo abordagem quantitativa (número de artigos) e qualitativa (impacto ou número de citações desses artigos publicados). Esse índice pode avaliar tanto a qualidade e o prestígio de um periódico ou o renome de um pesquisador.

Para se entender o cálculo, o índice-H de um pesquisador é o maior número " $\mathrm{h}$ " de artigos desse pesquisador com pelo menos o mesmo número " $\mathrm{h}$ " de citações cada um. Exemplificando, um cientista que tenha índice-H 10 significa que publicou, no mínimo, 10 artigos com 10 citações cada um. ${ }^{6}$ Quanto maior o índice, mais artigos e mais citações o pesquisador recebeu, e assim se avalia a qualidade de sua produção. Ainda que criado relativamente há pouco tempo, tal índice tornou-se parâmetro nas métricas acadêmicas. Para a Fapesp, ${ }^{7}$ ainda que o índice tenha limitações, ele se tornou "cartão de visitas" de pesquisadores, e influência nos momentos de contratação, por exemplo. ${ }^{8}$

O motivo pelo qual se escolheu o índice-H como objeto de análise nesta abordagem é o fato de o Google Acadêmico utilizá-lo (ver Figura 1) como umas das informações disponíveis sobre autores e periódicos, inclusive trazendo em seu texto de apresentação a seguinte citação: "As métricas do Google Acadêmico fornecem uma maneira fácil para os autores avaliarem rapidamente a visibilidade e a influência de artigos recentes em publicações acadêmicas". 9

Apresentada a metodologia e os dispositivos de análise, a seção a seguir faz a operacionalização entre os conceitos teóricos do poder disciplinar e panoptismo, discutidos na seção 2, ao material apresentado nessa seção.

6 Disponível em: http://www.seabd.bco.ufscar.br/bases-de-dados/metricas-da-ciencia/comocalcular-indice-h-de-um-pesquisador-na-web-of-science. Acesso em: 23 jul. 2019.

${ }^{7}$ Fundação de Amparo à Pesquisa do Estado de São Paulo - uma das mais renomadas agências de fomento à pesquisa do Brasil.

${ }^{8}$ Disponível em: http://revistapesquisa.fapesp.br/2013/05/14/os-limites-do-indice-h/. Acesso em: 23 jul. 2019.

${ }^{9}$ Disponível em: <https://scholar.google.com/intl/en/scholar/metrics.html\#overview>. Acesso em: 23 jul. 2019. 


\section{O poder disciplinar e o panóptico na academia}

Cada camarada torna-se um vigia.

(Foucault)

É saber notório que o dito do "Publique ou pereça" se encontra no cerne das práticas acadêmicas. Não faltam índices e métricas elaboradas e usadas a fim de medir a produtividade e o impacto da produção acadêmica de países, universidades, periódicos e pesquisadores. Alguém que já está inserido na academia e é ciente do funcionamento das suas práticas consegue elencar, rapidamente, várias dessas métricas - Qualis, fator de impacto, índice $G$, índice $H$, para citar algumas - e bancos de dados nos quais é possível encontrar essa quantificação - Google Scholar, Scopus, Web of Science, Scimago, Research Gate, entre outros.

Se o discurso para Foucault é o "conjunto de enunciados de determinado campo do saber", conforme já sinalizamos, regulado por uma matriz de sentido na qual os sujeitos inseridos dentro desse discurso se reconhecem, é possível agrupar os enunciados recorrentes na academia sob o escopo desse conceito, já que, ainda que "discurso acadêmico" seja uma terminologia genérica que abarca em si formações discursivas de várias áreas (Medicina, Letras, Biologia, entre outros), há uma regularidade, um posicionamento, uma função primeira em toda sua prática: a busca pelo conhecimento feita de maneira específica, calcada no método, no diálogo com teorias e pontos de vista anteriores, em resultados ou reflexões inéditas.

A função da maquinaria operada pelo discurso acadêmico, portanto, é a busca da(s) verdade(s), do saber, do desenvolvimento. Nessa maquinaria, várias engrenagens trabalham com a finalidade de manter o sistema em andamento. Ao expandirmos a tese de Díaz (2012), apresentada na seção 2, o poder dentro do discurso acadêmico funciona nos dispositivos concretos das universidades, instituições de pesquisa, métricas e banco de dados, como os citados, integrando as substâncias qualificadas (o pesquisador) e sua função básica (produção inédita de conhecimento científico).

Entretanto, não basta apenas a produção, é essencial haver o compartilhamento dessa produção entre os sujeitos desse discurso, o que pode ser feito por meio da publicação de textos acadêmicos, notadamente artigos científicos. Se há uma função produtora no discurso acadêmico, regulada por relações de poder, pode-se pensar no funcionamento de um poder disciplinar, via panóptico, como balizador dessas relações.

Como já apontamos na seção anterior, a função do Google Acadêmico não é apenas compilar os textos acadêmicos disponíveis, mas também elencá-los em ordem de impacto, medidos pelo índice-H. Dessa forma, possuirão maior visibilidade os textos e os pesquisadores que se encaixam na "normalidade" do discurso, criando os binarismos pesquisador que publica vs. pesquisador que não publica e pesquisador de impacto vs. pesquisador de nãoimpacto. Os que se enquadram na primeira parte da equação recebem reconhecimento, 
prestígio, oportunidades de emprego, bolsas, validação constante, discussão e perpetuação de seus teoremas. À segunda parte, é-lhes atribuído o status de improdutivos, gerando a punição de não receberem o mesmo tratamento e os mesmos louros.

Os dois princípios do cárcere panóptico - visibilidade e inverificabilidade - são mantidos. Analogamente, o Google Acadêmico e o Índice-H funcionam como as janelas da construção periférica que possibilitam a passagem de luz e a visibilidade de toda a cela. A organização de toda a produção de um pesquisador em um só lugar, organizada pelo impacto na área de interesse é a visibilidade: se ele publica, é visto - reconhece-se; se não publica, não é visto - esquece-se.

O princípio da inverificabilidade também ocorre. Ao ter sua produção disponibilizada e qualificada por meio dos dispositivos citados, o pesquisador não sabe quando, como e se suas obras serão lidas e/ou avaliadas pelo mundo exterior. Entretanto, a possibilidade de o serem faz com que continue operando dentro da dinâmica, da "normalidade" da maquinaria acadêmica, ou seja, publicando. Criam-se, constantemente, corpos dóceis, disciplinados, os quais validam o princípio dessa maquinaria.

Salientamos que, mesmo que tenha mantido os seus princípios básicos, o mecanismo de cárcere panóptico passou por uma sofisticação proveniente dos avanços tecnológicos, fato esse já previsto por Foucault (1999), ao considerar que na prisão poderia haver também algum tipo de vigilância no vigilante. Há uma certa subversão no sentido de que o mecanismo de vigilância, nesse caso, funciona em ambas as direções: a mesma tecnologia que coloca o pesquisador em posição de vigiado, permitindo que ele seja visto por outros, também permite que ele seja o vigilante. $O$ poder disciplinar passa a operar em várias camadas: há a vigilância (i) do mundo externo em relação ao pesquisador; (ii) do próprio pesquisador em relação a ele mesmo e sua produção; (iii) do pesquisador em relação ao mundo externo; e (iv) dos pesquisadores que compõem o mundo externo sobre eles próprios.

Esse funcionamento das instituições de ensino superior em torno da maquinaria de publicação científica acarreta consequências positivas e negativas para os corpos que nela se inscrevem. Um dos impactos positivos, sem dúvida, é o maior diálogo entre pesquisadores e instituições ao redor do mundo, propiciando maior desenvolvimento científico, uma vez que as pesquisas podem ser confirmadas, duplicadas para conferir maior credibilidade, aplicadas a outros contextos e aprimoradas.

Um exemplo de avanço científico propiciado pelas dinâmicas de pesquisa e publicação é a técnica Crispr. Foi publicado, na consagrada revista Nature, ${ }^{10}$ um artigo explicando uma nova técnica de edição do DNA, permitindo que ele seja cortado de forma mais rápida, fácil e barata do que a forma padrão usada pelos cientistas. Dessa forma, partes indesejadas do genoma, como os causadores de doença, podem ser eliminadas, e outras inseridas em seus lugares. Após a publicação da nova técnica, várias outras pesquisas pioneiras e revolucionárias

\footnotetext{
${ }^{10}$ Considerada uma das mais influentes e de maior visibilidade mundial.
} 
foram conduzidas ao longo de 2017, e publicadas para compartilhamento mundial, como, por exemplo, a aplicação de Crispr em testes para cura da Aids e doenças cardíacas. ${ }^{11}$

Em contrapartida ao florescimento científico propiciado pelo aumento de publicações, há impactos negativos gerados pela pressão para que pesquisadores se insiram, a qualquer custo, na maquinaria de publicação e, consequentemente, façam com que ela possa funcionar. Desses aspectos, podemos citar (i) a questão do plágio e do autoplágio, e, mais recentemente, (ii) a preocupação em torno da saúde mental dos pesquisadores.

As discussões em torno da questão autoral não são novas na academia. Devido à necessidade de publicações, alguns pesquisadores recorrem às práticas de plágio e autoplágio. Segundo o Relatório da Comissão de Integridade de Pesquisa do CNPq, plágio "consiste na apresentação, como se fosse de sua autoria, de resultados ou conclusões anteriormente obtidas por outro autor, bem como de textos integrais ou de parte substancial de textos alheios sem os cuidados detalhados nas Diretrizes", e autoplágio é a "apresentação total ou parcial de textos já publicados pelo mesmo autor sem as devidas referências aos trabalhos anteriores". ${ }^{12}$

Viana (2018) argumenta que essas práticas são consequências do capitalismo contemporâneo e dos processos de burocratização e mercantilização da academia. A produtividade exigida por esse contexto acarreta a competição entre as instituições e entre os pesquisadores. Uma das problemáticas envolvidas nessa competição é o não prezar pelo ineditismo da ciência, mas sim pelo reconhecimento, privilégio e recompensas, o que propicia um certo imediatismo que leva às práticas do plágio e autoplágio.

Krokoscz (2015) revela que $65 \%$ do corpus de trabalhos publicados na área de ciências sociais continham plágio, exemplificando o quão relevante é essa discussão para a academia. ${ }^{13}$ Em consonância com Viana (2018), Krokoscz (2015) afirma que o problema com as práticas de fraude autoral enfraquece a ciência, já que prejudica o ineditismo da ciência, função primordial do discurso acadêmico, e contribui para a má reputação dos pesquisadores que cometem o ato e dos periódicos científicos que publicam tais escritos.

Outro impacto negativo, consequência da exigência de uma produtividade científica exacerbada, gira em torno da saúde mental dos pesquisadores. A preocupação aumentou, principalmente, após casos de suicídios de pesquisadores brasileiros. Estudo conduzido na UFRJ aponta o alarmante dado de que, em 2009, 58,6\% dos pós-graduandos dessa instituição estavam estressados por motivos como a alta competitividade do meio acadêmico e a pressão

11 Disponíveis em: <https://g1.globo.com/ciencia-e-saude/noticia/veja-avancos-da-ciencia-queganharam-destaque-em-2017-e-desafios-que-ficam-para-o-proximo-ano.ghtml> https://www1.folha.uol.com.br/ciencia/2016/04/1764258-conheca-o-crispr-tecnica-de-edicao-dodna-que-promete-mudar-o-mundo.shtml. Acesso em: 23 jul. 2019.

12 Disponível em: <http://www.cnpq.br/documents/10157/a8927840-2b8f-43b9-89625a2ccfa74dda>. Acesso em: 23 jul. 2019.

${ }_{13}$ Disponível em: <http://www5.usp.br/96039/plagio-onde-esta-e-por-que-acontece/>. Acesso em: 23 jul. 2019. 
para publicação de artigos, características pontuadas aqui como base do poder disciplinar na maquinaria da academia universitária.

Outra pesquisa conduzida na Bélgica apresentou resultados semelhantes, afirmando ainda que, mais de um terço dos alunos estava sob alto risco de desenvolvimento de patologias sérias, como a depressão. Essa taxa é mais que o dobro do que a encontrada em pesquisas feitas em contextos não acadêmicos, e mostra que essa realidade não é exclusiva ao contexto brasileiro. ${ }^{14}$

Logo, afirma-se, de acordo com Foucault, que a operacionalização do poder na sociedade não carrega em si, necessariamente, um viés crítico no sentido de que é algo estritamente ruim ou bom, conforme ilustra Gicóia Junior (2016). O poder é uma força que existe e movimenta as relações entre os corpos sociais, incluindo-os ou excluindo-os do funcionamento das maquinarias. Dessa forma, para bem ou para mal, o poder disciplinar e o panóptico estão na base das dinâmicas das universidades, mais especificamente na pósgraduação, e é a engrenagem que faz com que a maquinaria da publicação científica não pare de funcionar.

\section{Conclusão}

Os animais são todos iguais, mas uns são mais iguais que outros.

(Orwell)

O objetivo do presente artigo foi refletir, com base no pensamento foucaultiano, sobre o poder disciplinar e o panoptismo como elementos atuantes no discurso acadêmico. Como percurso teórico, na introdução, procuramos situar Foucault no contexto sócio-histórico do pós-estruturalismo e abordar sua relação com o estruturalismo. Na seção seguinte, discutimos os conceitos de discurso, relações de poder, poder disciplinar e panóptico norteadores dessa abordagem.

Esses conceitos foram mobilizados, por meio de metodologia genealógica, na análise dos dispositivos do banco de dados Google Acadêmico e do índice-H de produtividade, conforme apresentados na seção de metodologia. Por fim, na seção de análise, fizemos o cotejo entre os conceitos e o material previamente apresentados, procurando mostrar, com base em nossa leitura, que os mecanismos da visibilidade e da inverificabilidade do panóptico atuam como balizadores das ações dos pesquisadores em discurso acadêmico.

Na análise, destacamos que os bancos de dados, como o Google Acadêmico, e métricas

\footnotetext{
14 Disponíveis em: https://www1.folha.uol.com.br/ciencia/2017/10/1930625-suicidio-dedoutorando-da-usp-levanta-questoes-sobre-saude-mental-na-pos.shtml. Acesso em: 23 jul. 2019.
} 
de produção, como o índice-H, são dispositivos atualizados e sofisticados do panóptico, conforme debatido por Foucault $(1979,1999)$. Por meio dos princípios da visibilidade e da inverificabilidade, o funcionamento do banco de dados permite que o poder disciplinar regule as relações do/no discurso acadêmico. Se a função principal da academia é produzir conhecimento científico e compartilhá-lo por meio de textos específicos, e isso pode ser visto e verificado como forma de reconhecimento e recompensas, os sujeitos, em movimento de validação da maquinaria, publicam e compartilham suas pesquisas acadêmicas. Assim, os pesquisadores se mantêm produtivos e se inserem na normalidade estabelecida pelas instituições que compõem a academia.

Em suma, consoante a epígrafe desta seção, vê-se que, nessa dinâmica corrente no discurso acadêmico, todos os sujeitos dessa maquinaria ocupam a posição de pesquisadores; entretanto, uns são considerados mais pesquisadores do que outros por atenderem aos requisitos estabelecidos pela maquinaria de produção acadêmica: não só publicam, mas também são vistos, de fato, pela comunidade. E o que confere esse status parece ser a visibilidade dessa estrutura panóptica.

\section{Referências}

CNPQ. Relatório da Comissão de Integridade de Pesquisa do CNPq. 2011. Disponível em: http://www.cnpq.br/documents/10157/a8927840-2b8f-43b9-8962-5a2ccfa74dda. Acesso em: 23 jul. 2019.

DÍAZ, E. A filosofia de Michel Foucault. Tradução de Cesar Candiotto. 1 ed. São Paulo: Editora Unesp, 2012. p. 85-148

ELSEVIER. Scopus. Disponível em: https://www.elsevier.com/pt-br/solutions/scopus. Acesso em: 23 jul. 2019.

FOUCAULT, M. A arqueologia do saber. Trad. Luiz Felipe B. Neves. 7 ed. Rio de Janeiro: Forense Universitária, $2008 . \quad$ Disponível em: http://www.uesb.br/eventos/pensarcomveyne/arquivos/FOUCAULT.pdf. Acesso em: 23 jul. 2019.

FOUCAULT, M. A ordem do discurso. Tradução de Laura Fraga de Almeida Sampaio. 20 ed. São Paulo: Edições Loyola, 2010.

FOUCAULT, M. Microfísica do poder. Tradução de Roberto Machado, Rio de Janeiro: Edições Graal, 1979. p. 167-228.

FOUCAULT, M. Vigiar e punir. E-book. Tradução de Raquel Ramalhete. 20 ed. Rio de Janeiro, Editora Vozes, 1999. Disponível em: http://escolanomade.org/wpcontent/downloads/foucault_vigiar_punir.pdf. Acesso em: 23 jul. 2019.

GIACOIA JUNIOR, O. Quem somos nós? Michel Foucault. Disponível em: https://www.youtube.com/watch?v=5XcxVHo4ozc. Acesso em: 23 jul. 2019.

GOOGLE ACADÊMICO. Métricas. Acesso em 27 ago 2018. Disponível em: 
https://scholar.google.com/intl/en/scholar/metrics.html\#overview. Acesso em: 23 jul. 2019. GOOGLE ACADÊMICO. Sobre o Google Acadêmico. Disponível em: https://scholar.google.com/intl/en/scholar/about.html. Acesso em: 23 jul. 2019.

GREGOLIN, M. do R. Foucault e Pêcheux na construção da análise do discurso - diálogos e duelos. São Carlos: Claraluz, 2004. p.17-64.

GREGOLIN, M. do R. O enunciado e o arquivo: Foucault (entre)vistas. In: SARGENTINI, Vanice; NAVARRO-BARBOSA, Pedro. (Org.). M. Foucault e os domínios da linguagem: discurso, poder e subjetividade. São Carlos: Claraluz, 2004. p. 23- 44.

HAEFFNER, C.; ZANOTTO, S. R. ZANOTTO; GUIMARÃES, J. A. Cultura dos indicadores em Ciência, Tecnologia e Inovação: panorama da produção científica nacional. 2015. Disponível em: http://www.comciencia.br/comciencia/handler. php?section=8\&edicao=111\&id=1328. Acesso em: 23 jul. 2019.

HARZING, A. L. Metrics: $h$ and g-index. Disponível em: https://harzing.com/resources/publishor-perish/tutorial/metrics/h-and-g-index. Acesso em: 23 jul. 2019.

MARTON, S. Café filosófico: Foucault, Deleuze e Derrida frente à crise. Disponível em: https://www.youtube.com/watch?v=mPBN2vYsOLI\&t=14s. Acesso em: 23 jul. 2019.

MORAES, F. T. Suicídio de doutorando da USP levanta questões sobre saúde mental na pós. Folha de São Paulo, São Paulo 27.10.18. Disponível em: https://www1.folha.uol.com.br/ciencia/2017/10/1930625-suicidio-de-doutorando-da-usplevanta-questoes-sobre-saude-mental-na-pos.shtml. Acesso em: 23 jul. 2019.

NAVARRO-BARBOSA, P. (org.). M. Foucault e os domínios da linguagem: discurso, poder, subjetividade. São Carlos: Claraluz, 2004, p. 23-44.

OKSALA, J. Como ler Foucault. Tradução de Maria Luiza X. de A. Borges. Rio de Janeiro: Zahar, 2011.

OLIVEIRA, L. A. (Org.) Estudos do discurso: perspectivas teóricas. São Paulo: Parábola Editorial, 2013.p.123-152.

PETERS, M. Pós-estruturalismo e filosofia da diferença. Tradução de Tomaz Tadeu da Silva. Belo Horizonte: Autêntica, 2000. p.9-46

REVISTA FAPESP. Os limites do índice H. Disponível em: http://revistapesquisa.fapesp.br/2013/05/14/os-limites-do-indice-h/. Acesso em: 23 jul. 2019.

SAUSSURE, F. Curso de linguística geral. 26 ed. São Paulo: Cultrix, 2004

SEABD. Como calcular Índice-H de um pesquisador na Web of Science. Disponível em: http://www.seabd.bco.ufscar.br/bases-de-dados/metricas-da-ciencia/como-calcular-indiceh-de-um-pesquisador-na-web-of-science. Acesso em: 23 jul. 2019.

SILVA, P. M.; MOTA, T. R. A.; Mello, J. C. C. S. Avaliação da utilização do índice h como ferramenta de medição da produção científica do programa de pós-graduação em engenharia de produção da universidade federal fluminense. Relatórios de pesquisa em engenharia de produção, v.14, n. A5, p. 52-60. 
SILVA, F. P. Articulações entre poder e discurso em Michel Foucault. In: SARGENTINI, V; NAVARRO-BARBOOSA, P. (org.). M. Foucault e os domínios da linguagem: discurso, poder, subjetividade. São Carlos: Claraluz, 2004, p. 159-182.

USP. Plágio: onde está $e$ por que acontece?. 2015. Disponível em: http://www5.usp.br/96039/plagio-onde-esta-e-por-que-acontece/. Acesso em: 23 jul. 2019.

VEIGA-NETO, A. Foucault e a educação. Belo Horizonte: Autêntica, 2007.

VIANA, N. Reflexões sobre plágio e autoplágio. 2018. Disponível em: http://informecritica.blogspot.com/2018/01/reflexoes-sobre-plagio-e-autoplagio.html.

Acesso em: 23 jul. 2019.

Recebido em: 12/03/2019

Aceito em: 17/08/2019 